\title{
Studies on Physiological Characteristics of Sarocladium oryzae Causing Sheath Rot of Rice
}

\author{
K.K. Panda* and M.K. Mishra \\ Department of Plant Pathology, OUAT, Bhubaneswar (Odisha) 751003, India \\ *Corresponding author
}

\section{A B S T R A C T}

\section{Keywords}

Sheath rot, Radial growth, Mycelial dry weight,

Sarocladium oryzae

Article Info

Accepted:

15 July 2019

Available Online:

10 August 2019

Studies were conducted in the Dept. of Plant Pathology of Odisha University of Agriculture and Technology, Bhubaneswar for the various physiological requirements of Sarocladium oryzae causing sheath rot of rice. It was revealed that Potato dextrose agar supported significantly maximum radial growth $(74.0 \mathrm{~mm})$ followed by Sabouraud's medium $(71.8 \mathrm{~mm})$ and Czapek's dox medium $(70.0 \mathrm{~mm})$. Significantly dry weight of mycelial mat was maximum at $\mathrm{pH} 4.0$ (769.0mg) followed by $\mathrm{pH} 3.5$ (746.6 mg). The highest radial growth was observed in 12 hour light and 12 hour darkness $(68.1 \mathrm{~mm})$ closely followed by 8 hour light and 16 hour darkness $(61.5 \mathrm{~mm})$ significantly. Maximum radial growth of $S$. oryzae was observed in $30^{\circ} \mathrm{C}(65.0 \mathrm{~mm})$ followed by growth in $35^{\circ} \mathrm{C}(58.0 \mathrm{~mm})$ significantly.

\section{Introduction}

Rice (Oryza sativa L.) is a versatile crop which is cultivated for its grain used as staple food in most parts of the world. In Odisha, rice is grown under diverse ecosystems and a wide range of climatic conditions. Jeypore tract in South Odisha has been identified as a putative secondary center of origin of cultivated rice (Ramiah and Ghose, 1951, Ramiha and Rao, 1953).

The potential yield of rice suffers major setback by natural calamities like flood, dry spell and biotic factors like disease pest.
Annual yield loss in rice due to pests and diseases is $35-40 \%$ (Srinivasachary et al., 2002). Rice suffers from 50 diseases including 21 fungal, 6 bacterial, 12 viral, 4 nematodes and 7 miscellaneous diseases and disorders (Hollier et al., 1993; Webster and Gunnell, 1992; Jabeen et al., 2012).

Among the fungal diseases, sheath rot of rice caused by Sarocladium oryzae (Sawada) Gams and Hawksworth (1922), is gaining the status of major disease due to widespread occurrence in almost all rice growing areas of the world including India (Reddy and Gosh, 1985). The yield loss varied from 9.6 to $85 \%$, 
depending on the weather conditions during the crop growth-period (Phookan and Hazarika, 1992). After the introduction of hybrid rice varieties, sheath rot is considered as third major fungal disease after blast and sheath blight because of continuous occurrence and heavy yield loss caused by it. The disease occurs in varied temperature and climate.

An investigation was carried out in the Dept. of Plant Pathology, College of Agriculture, Odisha University of Agriculture and Technology, Bhubaneswar for the various physiological requirements of Sarocladium oryzae causing sheath rot of rice.

\section{Materials and Methods}

\section{Growth behaviour of S.oryzae in different} solid media

In this case fifteen solid media viz. Potato dextrose agar, Richard's medium, Brown's medium, Czapek's dox medium, Coon's medium, Kirchhoff's medium, Sabourd's medium, Potato sucrose agar, Yeast dextrose agar, Oat meal agar, Potato rose bangle, Host leaf extract agar, Potato carrot agar, Water agar, Nutrient sucrose agar were taken for testing the growth behavior of S.oryzae. Each medium was sterilized at 15 p.s.i $\left(121.6^{\circ} \mathrm{C}\right)$ for 20 minutes. After sterilization of total fifteen media, $20 \mathrm{ml}$ of each media was poured in sterilized petridish aseptically.

The effect of different media on fungal growth (S.oryzae) was tested in solid conditions. Fifteen days old culture of test pathogen was inoculated at the center of petriplate through sterilized inoculation needle and three replications of each treatment were maintained. These petriplates were incubated at $27 \pm 1^{\circ} \mathrm{C}$ in incubator and observed periodically. Observation was taken on the radial mycelial growth of the fungus.

\section{Effect on hydrogen ion concentration on growth of S.oryzae}

In order to study the optimum $\mathrm{pH}$ required for growth of the fungus potato dextrose broth was adjusted to different $\mathrm{pH}$ levels i.e. $\mathrm{pH}$ of $3.5,4.0,4.5,5.0,5.5,6.0,6.5,7.0,7.5,8.0,8.5$ and 9.0 using a digital $\mathrm{pH}$ meter by adding standard sodium hydroxide and hydrochloric acid. One hundred $\mathrm{ml}$ of each of the adjusted medium was poured into $250 \mathrm{ml}$ conical flasks separately and sterilized by autoclave and then allowed to cool. The $\mathrm{pH}$ level of medium after sterilization was found unaltered.

The fungus was inoculated in the broth having different $\mathrm{pH}$, aseptically. Each treatment was replicated three times.

After 20 days of inoculation the mycelia mats were filtered through previously weighed filter papers separately. These mycelial mats along with the filter paper were oven dried at constant $60^{\circ} \mathrm{C}$ for 1 hour. Then the dry weight of the filtered mass was taken using a digital balance. Finally, the weight of the respective filter papers was subtracted to get the net weight of the fungal biomass and the results were analyzed statistically.

\section{Growth behavior of S.oryzae to different light exposure}

Optimum growth of test fungus was also carried out in different light period exposure. Twenty days old culture of S.oryzae was inoculated in centre of sterilized petridishes containing potato dextrose agar (PDA) for 15 days. Three replications of each treatment were maintained.

These inoculated petriplates were subjected to different light sources, namely, (1) $4 \mathrm{hrs}$ exposure to sunlight: - The petriplates were exposed to sunlight immediately after inoculation for $4 \mathrm{hrs}$ and rest of time were 
kept on the laboratory table 2 Continuous darkness: - The inoculated petriplates were kept inside the beaker and covered with black cloth for 15 days. (3) Continuous light: - It was kept on the wooden table with 60 watts electrical bulb maintained $50 \mathrm{~cm}$ away from the top of the inoculated petriplates. (4) 8hrs darkness and 16 hrs light: - the inoculated petriplates were kept inside the black cloth covered beaker for $8 \mathrm{hrs}$ and on the table for $16 \mathrm{hrs}$ light. (5) $16 \mathrm{hrs}$ darkness and $8 \mathrm{hrs}$ light: - It was also maintained like above procedures. (6) $12 \mathrm{hrs}$ light and $12 \mathrm{hrs}$ darkness: - the alternate light and darkness was maintained by using black cloth covered beaker and electrical bulb. (7) 10 minutes exposed to UV light. (8) 20 minutes exposed to UV light.

For these, the petriplates were inoculated in laminar air flow chamber and exposed to UV light for 10 and 20 minutes immediately after inoculation and kept on the laboratory table. (9) Natural diffused light under laboratory condition: - The alternate light and darkness occurred automatically under laboratory condition. The observation was taken after 15 days of inoculation.

\section{Optimum temperature requirement for the growth of $S$. oryzae}

The effect of different temperatures on growth of S.oryzae was tested on PDA medium. The potato dextrose agar medium was sterilized and twenty $\mathrm{ml}$ of melted PDA medium was poured into sterilized petridish aseptically and allowed to cool. Five mm mycelial disc of 20 days old culture was cut by sterilized cork borer and placed in the centre of each petriplate and three replications were maintained in each case. These were labeled at different temperature viz., $5 \pm 1^{0}, 10 \pm 1^{\circ}, 15 \pm 1^{\circ}$, $20 \pm 1^{\circ}, 25 \pm 1^{\circ}, 30 \pm 1^{\circ}, 35 \pm 1^{\circ}$ and $40 \pm 1^{\circ} \mathrm{C}$ and incubated in incubator for 15 days. The colony diameter was recorded.

\section{Results and Discussion}

\section{Growth behaviour of S.oryzae in different solid media}

Different sets of solid media were used to study the suitability of the media to support maximum radial growth of the test fungus. Potato dextrose agar supported maximum radial growth $(74.0 \mathrm{~mm})$ which was significantly the highest among all the media followed by Sabourd's medium $(71.8 \mathrm{~mm})$ and Czapek's dox medium (70.0mm).Coon's medium and yeast dextrose agar, Richard's medium, potato carrot agar, Kirchhoff's medium, Host leaf extract agar behaved similarly for the growth of S.oryzae. Minimum radial growth was observed in potato rose bangle (32.00mm). Prabhakaran et al., (1974) reported that Potato dextrose agar (PDA) as the best medium than Czapeck's medium for the growth of Sarocladium oryzae. Mohan and Subramanian (1978) observed that Potato dextrose agar (PDA) and Oat agar (OA) media support the growth of the pathogen significantly better than other media tested. Very good sporulation was observed in PDA, oat agar and Czapeck's dox agar media (Table 1 and Fig. 1).

\section{Effect on hydrogen ion concentration on growth of S.oryzae}

The test fungus was grown on different $\mathrm{pH}$ regime from 3.5 to 9.0. Dry weight of the test fungus was taken after 20 days of inoculation. Significant growth difference was observed among all the $\mathrm{pH}$ level with highest mycelial mat of $769.0 \mathrm{mg}$ in $\mathrm{pH} 4.0$ followed by 746.6 in $\mathrm{pH}$ 3.5. The production of dry mycelial weight was slowly declined from lower $\mathrm{pH}$ to higher $\mathrm{pH}$ with $\mathrm{pH} 8.5$ recording lowest mycelial weight $(404.00 \mathrm{mg})$. Nearly all the consecutive $\mathrm{pH}$ ranges i.e. $\mathrm{pH} 3.5$ and $4.0, \mathrm{pH}$ 6.0, 6.5 and 7.0, $\mathrm{pH} 7.5$ and 8.0, $\mathrm{pH} 8.5$ and 9.0 behaved similarly in supporting the growth 
of S.oryzae. Mithrasena and Wijesundera also stated good mycelia growth of sheath rot (1992) observed maximum growth of $S$. fungus at $\mathrm{pH} 6.4$ which confirmed the current oryzae in $\mathrm{pH}$ 3.5. Tasuki and Ikeda (1956) findings (Table 2 and Figure 2).

Table.1 Growth behaviour of S.oryzae in different solid media

\begin{tabular}{|l|l|c|}
\hline Sl. no & \multicolumn{1}{|c|}{ Media } & Mean radial growth $(\mathbf{m m})$ \\
\hline $\mathbf{1}$ & Potato dextrose agar & 74.0 \\
\hline $\mathbf{2}$ & Richard's medium & 62.2 \\
\hline $\mathbf{3}$ & Brown's medium & 67.7 \\
\hline $\mathbf{4}$ & Czapek's dox medium & 70.0 \\
\hline $\mathbf{5}$ & Coon's medium & 62.0 \\
\hline $\mathbf{6}$ & Yeast dextrose agar & 62.8 \\
\hline $\mathbf{7}$ & Kirchhoff's medium & 63.7 \\
\hline $\mathbf{8}$ & Sabourd's medium & 71.8 \\
\hline $\mathbf{9}$ & Potato sucrose agar & 67.8 \\
\hline $\mathbf{1 0}$ & Oat meal agar & 52.5 \\
\hline $\mathbf{1 1}$ & Potato rose bangle & 32.0 \\
\hline $\mathbf{1 2}$ & Host leaf extract agar & 63.2 \\
\hline $\mathbf{1 3}$ & Potato carrot agar & 60.5 \\
\hline $\mathbf{1 4}$ & Water agar & 51.2 \\
\hline $\mathbf{1 5}$ & Nutrient sucrose agar & 68.2 \\
\hline & SE(m) \pm & $\mathbf{1 . 8}$ \\
& & $\mathbf{5 . 2}$ \\
\hline
\end{tabular}

Table.2 Effect on hydrogen ion concentration on growth of S.oryzae

\begin{tabular}{|l|c|c|}
\hline Sl. no & pH level & Dry weight of mycelium $(\mathbf{m g})$ \\
\hline $\mathbf{1}$ & 3.5 & 746.7 \\
\hline $\mathbf{2}$ & 4.0 & 769.0 \\
\hline $\mathbf{3}$ & 4.5 & 697.3 \\
\hline $\mathbf{4}$ & 5.0 & 657.3 \\
\hline $\mathbf{5}$ & 5.5 & 580.7 \\
\hline $\mathbf{6}$ & 6.0 & 525.3 \\
\hline $\mathbf{7}$ & 6.5 & 523.0 \\
\hline $\mathbf{8}$ & 7.0 & 518.7 \\
\hline $\mathbf{9}$ & 7.5 & 462.3 \\
\hline $\mathbf{1 0}$ & 8.0 & 473.0 \\
\hline $\mathbf{1 1}$ & 8.5 & 404.0 \\
\hline $\mathbf{1 2}$ & 9.0 & 414.0 \\
\hline & SE(m) & $\mathbf{1 3 . 5}$ \\
& CD @ $\mathbf{5 \%}$ & $\mathbf{3 9 . 8}$ \\
\hline
\end{tabular}


Table.3 Growth behaviour of S.oryzae to different light exposure

\begin{tabular}{|l|l|c|}
\hline Sl. no & \multicolumn{1}{|c|}{ Light period } & $\begin{array}{l}\text { Mean of Radial } \\
\text { growth (mm) }\end{array}$ \\
\hline $\mathbf{1}$ & Sunlight (4hr exposure) & 5.7 \\
\hline $\mathbf{2}$ & Continuous Dark light & 57.6 \\
\hline $\mathbf{3}$ & Continuous light & 40.6 \\
\hline $\mathbf{4}$ & 8hr darkness\&16 hr light & 59.5 \\
\hline $\mathbf{5}$ & 16 hr darkness\&8hr light & 61.5 \\
\hline $\mathbf{6}$ & 12hr light\&12 hr darkness & 68.1 \\
\hline $\mathbf{7}$ & 10min exposed to UV light & 35.3 \\
\hline $\mathbf{8}$ & 20 min exposed to UV light & 33.0 \\
\hline $\mathbf{9}$ & Natural diffused light under laboratory & 53.7 \\
\hline & SE(m) & $\mathbf{2 . 7}$ \\
& CD @ 5\% & $\mathbf{8 . 0}$ \\
\hline
\end{tabular}

Table.4 Optimum temperature requirement for the growth of S. oryzae

\begin{tabular}{|c|c|c|}
\hline Sl. no & Temperature $\left({ }^{0} \mathrm{C}\right)$ & $\begin{array}{l}\text { Mean of radial } \\
\text { growth }(\mathbf{m m}) *\end{array}$ \\
\hline 1 & 5 & $\begin{array}{c}0.0 \\
(0.71)\end{array}$ \\
\hline 2 & 10 & $\begin{array}{l}21.0 \\
(4.63)\end{array}$ \\
\hline 3 & 15 & $\begin{array}{l}30.66 \\
(5.58)\end{array}$ \\
\hline 4 & 20 & $\begin{array}{l}36.33 \\
(6.06)\end{array}$ \\
\hline 5 & 25 & $\begin{array}{c}42.0 \\
(6.51)\end{array}$ \\
\hline 6 & 30 & $\begin{array}{c}65.0 \\
(8.09)\end{array}$ \\
\hline 7 & 35 & $\begin{array}{c}58.0 \\
(7.64)\end{array}$ \\
\hline \multirow[t]{2}{*}{8} & 40 & $\begin{array}{l}24.66 \\
(5.01)\end{array}$ \\
\hline & $\begin{array}{c}\mathrm{SE}(\mathrm{m})^{ \pm} \\
\mathrm{CD} @ \mathbf{5 \%}\end{array}$ & $\begin{array}{l}0.10 \\
0.30\end{array}$ \\
\hline corre & $\begin{array}{l}\text { Ires in the } \\
\text { ing } \sqrt{[x+0.5]} \text { trans }\end{array}$ & $\begin{array}{l}\text { thesis indicat } \\
\text { value }\end{array}$ \\
\hline
\end{tabular}


Fig.1 Growth behaviour of S.oryzae in different solid media

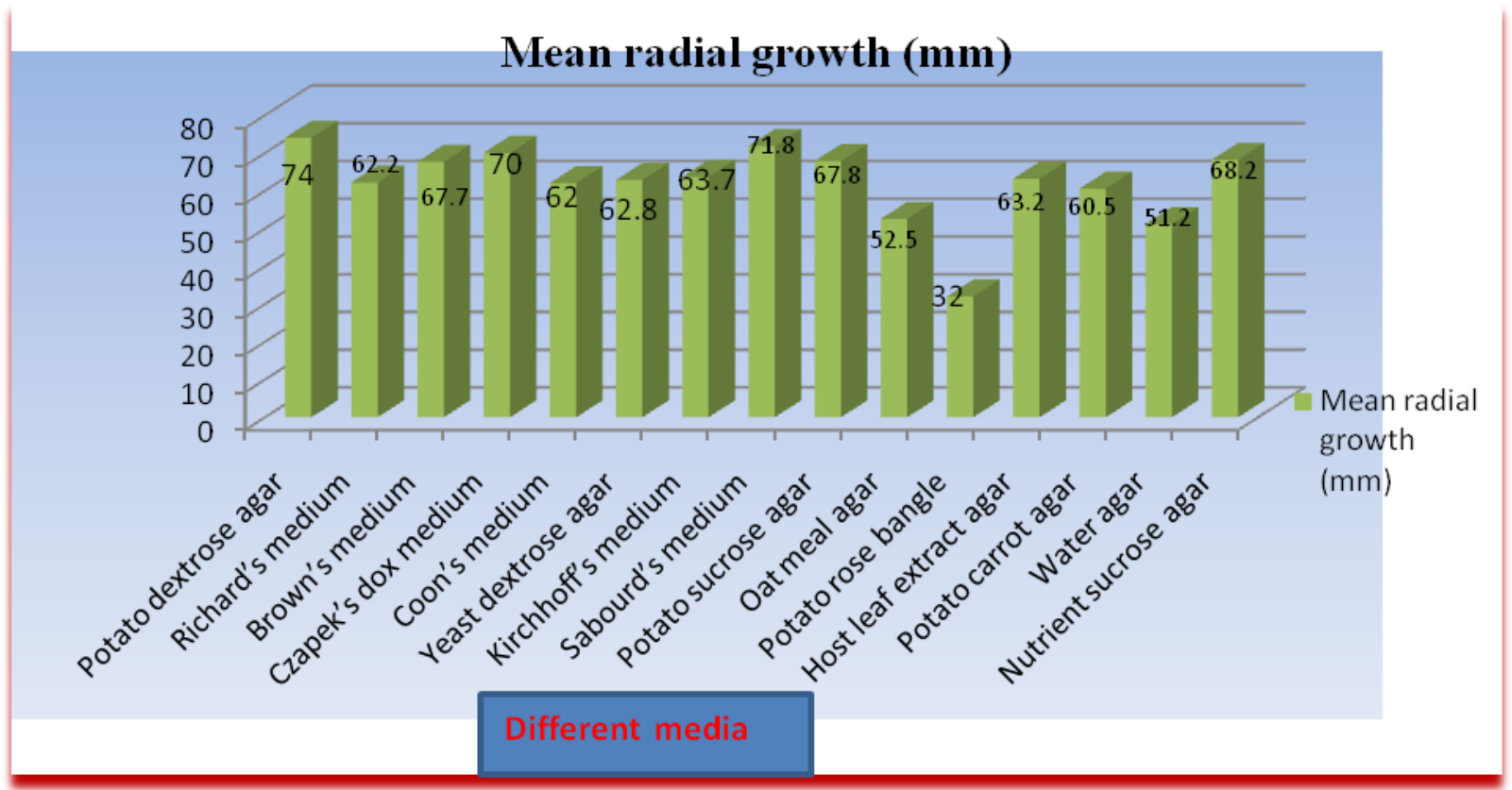

Fig.2 Effect on hydrogen ion concentration on growth of S.oryzae

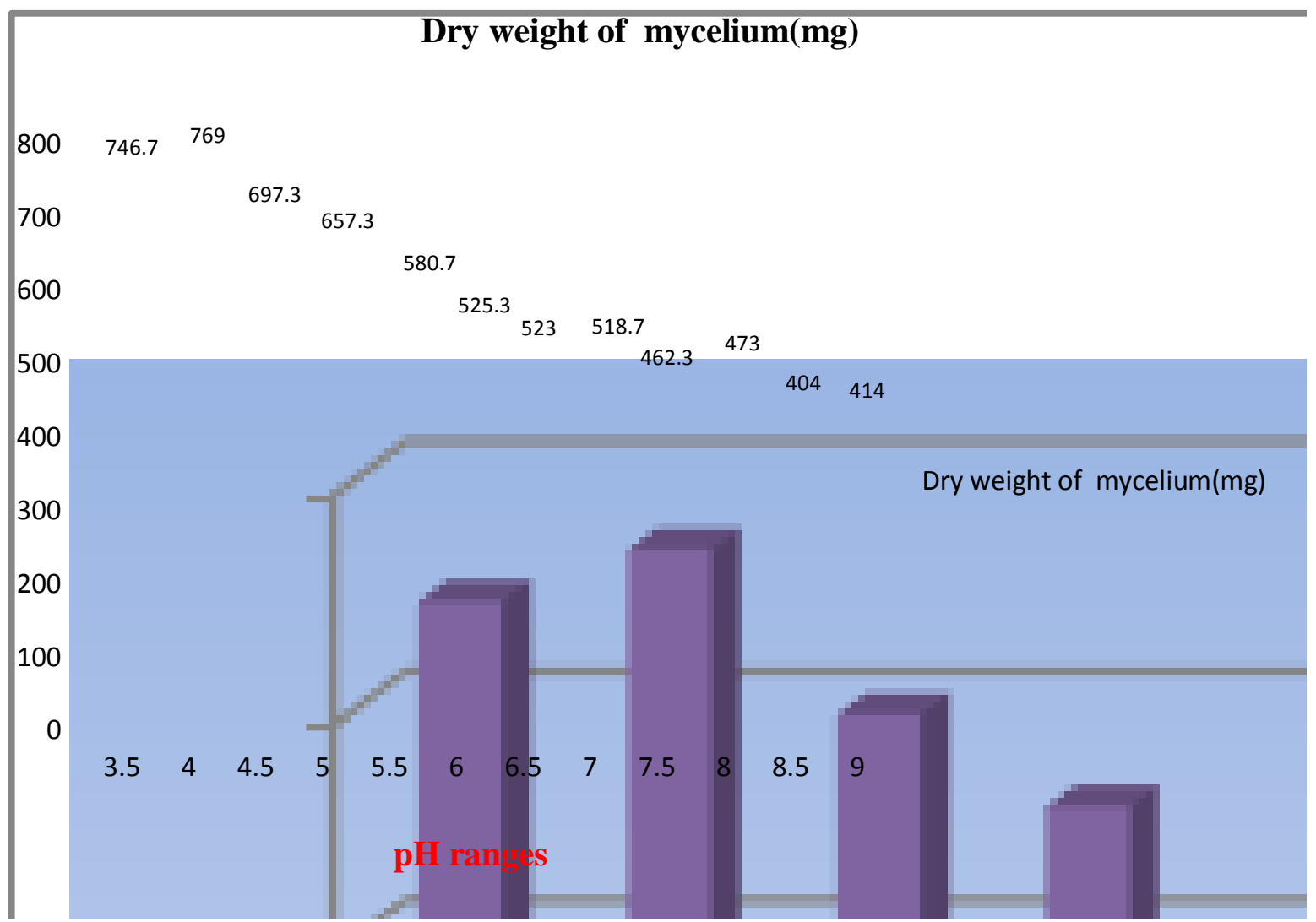


Fig.3 Growth behaviour of S.oryzae to different light exposure

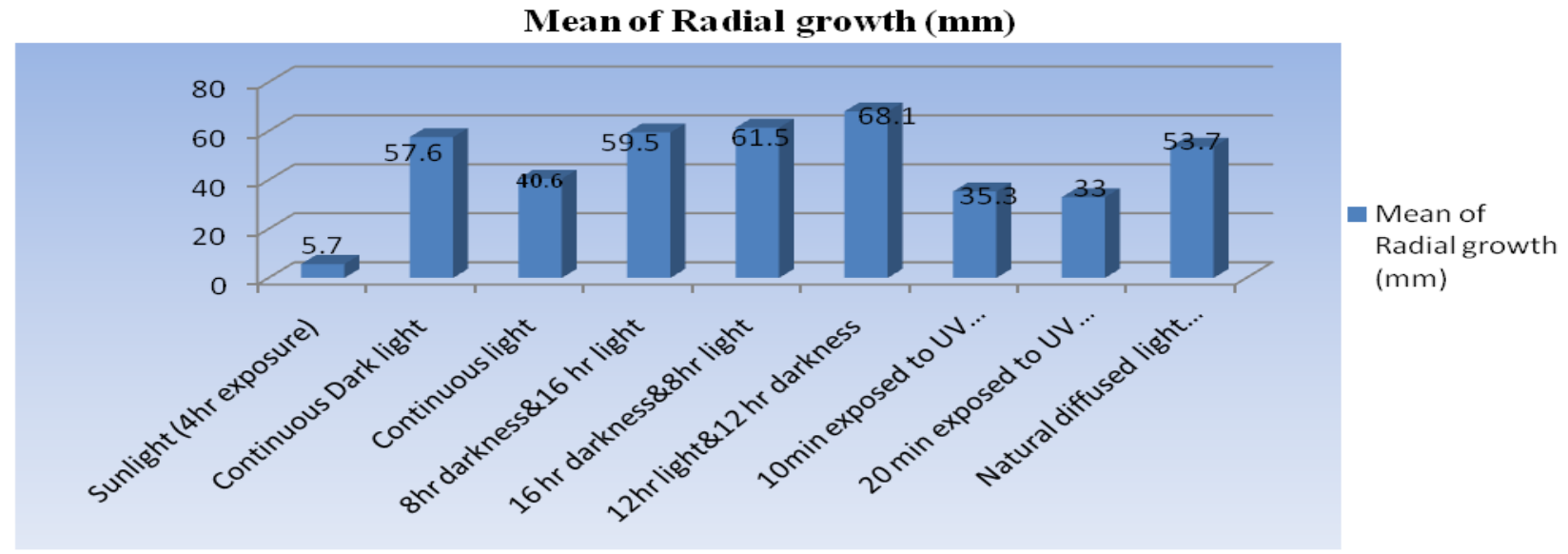

Fig.4 Optimum temperature requirements for the growth of $S$. oryzae

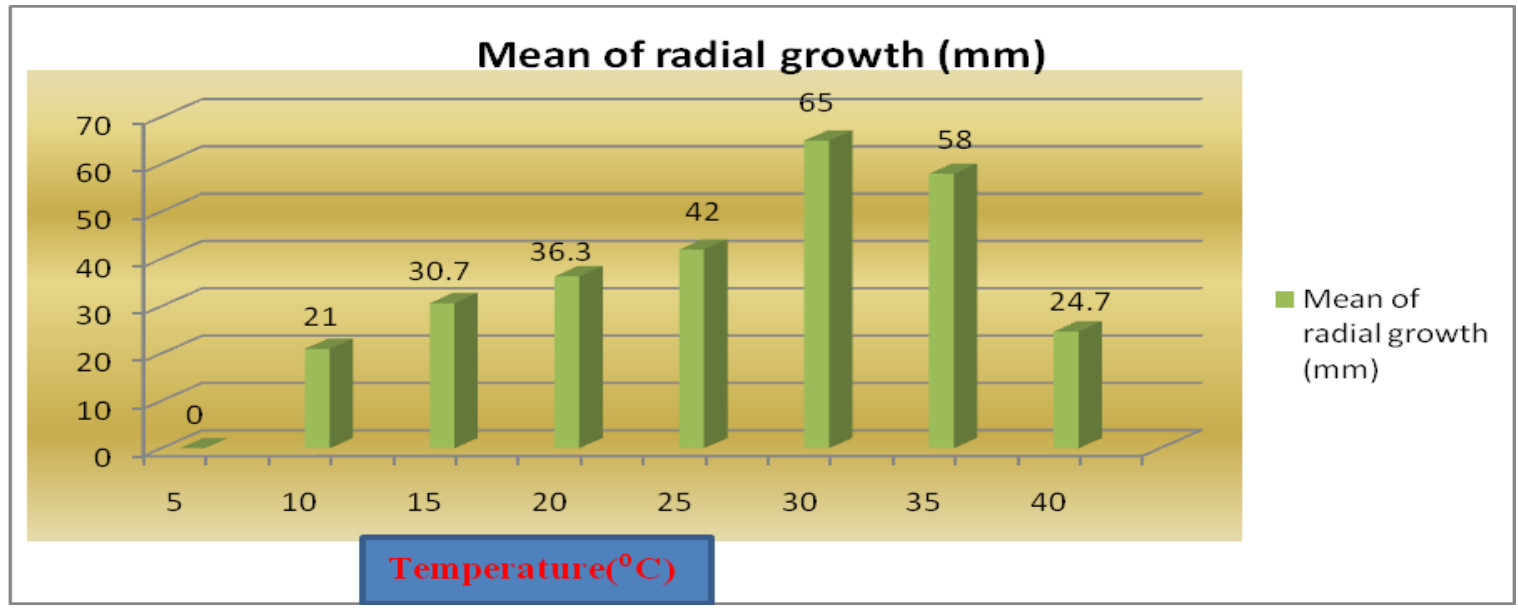

Growth behaviour of $S$. oryzae to different light exposure

Rate of growth of $S$. oryzae was studied in different light exposure.

Varied growth differences were observed among all the light exposure with highest growth of $68.1 \mathrm{~mm}$ in 12 hour light and 12 hour darkness closely followed by $8 \mathrm{hr}$ light and 16 hr darkness $(61.5 \mathrm{~mm})$. S.oryzae did not respond $\mathrm{t}$ bright sunlight and fungal growth was very slow i.e only $5.7 \mathrm{~mm}$ in 15 days of growth period. Mithrasena and Wijesundera (1992) revealed that sporulation of $S$. oryzae was enhanced by exposure of fungal colonies to $12 \mathrm{~h}$ light and $12 \mathrm{~h}$ darkness. The current findings also confirmed the work of above workers (Table 3 and Figure 3).

\section{Optimum temperature requirement for the} growth of $S$. oryzae

Growth behaviour of $S$. oryzae in different temperature ranges was also estimated. Significant radial growth difference was observed among all the temperature tested. Maximum growth of $S$. oryzae was observed in $30^{\circ} \mathrm{C}(65.0 \mathrm{~mm})$ followed by growth in $35^{\circ} \mathrm{C}$ $(58.0 \mathrm{~mm})$. Similar growth pattern was recorded by Mohan and Subramanian (1978) i.e. maximum growth and sporulation of the fungus 
S. oryzae on oat agar medium. Shahjahan et al., (1977) also got best growth and conidia formation of $S$. oryzae on PDA at $32^{\circ} \mathrm{C}$. In the current study, reduced radial growth was observed as the temperature was increased for $30^{\circ} \mathrm{C}$ to $40^{\circ} \mathrm{C}$, but radial growth of $S$. oryzae was increased from $5^{\circ} \mathrm{C}$ upto $30^{\circ} \mathrm{C}$ with no growth at all at $5^{\circ} \mathrm{C}$ (Table 4 and Figure 4).

\section{Acknowledgement}

The authors are highly thankful to the Prof. and Head, Plant Pathology, college of Agriculture, OUAT, Bhubaneswar for providing the facility to the current research work.

\section{References}

Hollier CA, Groth DE, Rush MC and Webster RK (1993). Common Names of Plant Diseases. The American Phytopathological Society, St. paul, MN.

Jabeen R, Iftikhar $\mathrm{T}$ and Batool H. (2012). Isolation, characterization, preservation and pathogenicity test of Xantomonas oryzae $\mathrm{PV}$. Causing BLB disease in rice. 44(1): 261-265.

Mithrasena, Y. J.P.K. and Wijesundera, R. L. C., (1992).Growth and sporulation of Sarocladium oryzae, the rice sheath rot pathogen, Trop. Agriculturist, 148: 1-13.

Mohan, R. and Subramanian, C. L., (1978). Growth studies on Acrocylindrium oryzae Sawada an incitant of sheath rot disease of rice. Madras Agric. J., 65(2): 172-175.

Phookan, A. K. and D. K. Hazarika, (1992). Distribution of sheath rot (ShR) in six agroclimatic zones of Assam, India. IRRN. 17: 16.

Prabhakaran, J., Ragunathan, V. and Prasad, N.N. (1974). Occurrence of sheath rot of rice caused by Acrocylindrium oryzae Sawada. Annamalai University Agricultural Research Annual. 4: 182183.

Ramiah K, Ghose RLM. (1951). Origin and distribution of cultivated plants of South Asia: rice. Indian J. Genet. Plant Breed. 11: 7-13

Ramiah K, Rao MBVN. (1953). Rice breeding and genetics. Indian Council of Agricultural Research, New Delhi.

Reddy, C. S. and A. Gosh, (1985). Sheath rot incidence and yield losses in rice due to the joint infection of rice tungro virus and sheath rot fungus. Indian Phytopath 38(1): 165-167.

Sawada, K. (1922). Descriptive catalogue of for mason fungi II, Rep. Govt. Inst. Dep. Agric., Formosa, 2: 136.

Shahjahan, A.K.M., Harahap, Z. and Rush, M.C. (1977). Sheath rot of rice caused by Acrocylindrium oryzae in Lousiana. Plant Dis. Reprt., 61: 307-310.

Srinivasachary H, Shailaja K, Girishkumar H.E, Shashidhar and M.G Vaishali (2002). Identification of quantitative trait loci associated with sheath rot (Sarocladium oryzae) resistance and panicle exsertion in rice (Oryza sativa L.). Current sci., 82: 133-135.

Tasugi, H. and Y. Ikeda, (1956). Studies on sheath rot of rice plant caused by Acrocylindrium oryzae Sawada. Bulletin of the National Institute of Agricultural Sciences 6: 151-166.

Webster RK and Gunnell PS. 1992. Compendium of Rice Diseases. The American phytopathological Society, St. paul, MN. 86.

\section{How to cite this article:}

Panda, K.K. and Mishra, M.K. 2019. Studies on Physiological Characteristics of Sarocladium oryzae Causing Sheath Rot of Rice. Int.J.Curr.Microbiol.App.Sci. 8(08): 1767-1774. doi: https://doi.org/10.20546/ijcmas.2019.808.209 